HEALTH-RELATED QUALITY OF LIFE OF NIGERIAN CHILDREN WITH EPILEPSY

\title{
QUALITÉ DE VIE CHEZ DES ENFANTS NIGÉRIANS ÉPILEPTIQUES
}

LAGUNJU IkeOluwa Abiola ${ }^{1}$

AKINYINKA Olusegun ${ }^{1}$

ORIMADEGUN Adebola 1

AKINBAMI Felix Olukayode ${ }^{1}$

BROWN Biobele Jotham ${ }^{1}$

OLORUNDARE Elizabeth ${ }^{1}$

OHAERI Jude ${ }^{2}$

1. Department of Paediatrics, University College Hospital, Ibadan, Nigeria

2. Department of Psychiatry, University College Hospital, Ibadan, Nigeria

E-Mail Contact - LAGUNJU IkeOluwa Abiola : ilagunju (at) yahoo (dot) co.uk

Mots-clés: Enfant, Epilepsie, Qualité de vie, Nigeria

Keywords: Children, Epilepsy, Quality of life, Nigeria

\section{RESUME}

\section{Contexte}

L'épilepsie est un trouble neurologique de l'enfant entrainant une charge lourde dans les pays en développement. La gestion de l'épilepsie comprend le contrôle optimal de la maladie, ainsi que l'amélioration de la qualité de vie (HRQOL) des enfants touchés.

\section{Objectifs}

Cette étude a été menée afin d'évaluer l'HRQOL des enfants nigérians atteints par l'épilepsie ainsi que l'impact psychosocial de la maladie sur les parents des enfants concernés.

\section{Méthodes}

Un questionnaire normalisé adapté de la PedsQL questionnaire a été appliqué pour évaluer les HRQOL chez 66 consécutifs enfants épileptiques, âgés de $\geq 5$ années à l'University College Hospital, Ibadan au cours d'une période de 3 mois.

\section{Résultats}

Vingt enfants $(30,3 \%)$ ont montré d'importantes déficiences dans le HRQOL avec un impact majeur dans les domaines de la santé en général, la vie familiale, scolaire et l'estime de soi. II y avait une association statistiquement significative entre la gravité de saisie, l'autorité parentale, l'impact émotionnel, le niveau d'éducation maternelle.

\section{Conclusion}

Les atteintes de la qualité de vie (HRQOL) est un problème majeur au Nigeria chez les enfants épileptiques. Le soutien familial étendu ne semble pas avoir d'effet sur l'amélioration du stress vécu. Cette étude suggère la nécessité d'un soutien psychosocial chez les enfants traités par les antiépileptiques. 


\section{SUMMARY}

\section{Background}

Epilepsy is a leading neurological disorder in childhood with the greatest burden in developing countries. The scope of management of epilepsy includes optimal seizure control as well as improvement of the health related quality of life $(\mathrm{HRQOL})$ of affected children.

\section{Objectives}

The study was undertaken to assess the HRQOL of Nigerian children with epilepsy and the psychosocial impact of the disease on the parents of affected children.

\section{Methods}

A standardized questionnaire adapted from the PedsQL Questionnaire was applied to evaluate the HRQOL in 66 consecutive children with epilepsy, aged $\geq 5$ years seen at the University College Hospital, Ibadan during a 3 month period.

\section{Results}

Twenty children $(30.3 \%)$ showed significant impairment in the HRQOL with the major impact found in the areas of general health, family life, school activity and self esteem. There was a statistically significant association between seizure severity, parental emotional impact, maternal level of education and impaired HRQOL.

\section{Conclusion}

Impaired HRQOL is a major issue in Nigerian children with epilepsy. The extended family support system does not appear to have any ameliorating effect on the stress experienced by the affected families. This study suggests the need for psychosocial support to achieve optimal care for children on antiepileptic drugs.

\section{INTRODUCTION}

Epilepsy is a significant neurological problem in developing countries $(2,12)$ and has been associated with significant psychosocial maladjustment in both the affected children and family $(4,8,19)$. Freilinger et al $(8)$ in Austria reported behavioural and emotional problems in $22 \%$ of epileptic children and studies have described feelings of shame, rejection, fear, worry, low self esteem and perception of stigma as common in children with epilepsy $(6,9,18)$.

Epilepsy also has significant emotional impact on parents of affected children and parental emotional stability has been found to be a major predictor of the quality of life of the epileptic child (4). Increasing attention is being focused on problems experienced by people with epilepsy as a result of stigma which is associated with poor psychosocial health outcomes and impaired quality of life (15). Epilepsy may interfere with social functioning by limiting educational opportunities, employability and interpersonal relationships as well as increase the risk of death (15). Aldenkamp et al (1) in the Netherlands, reported high a quality of life in a group of individuals with epilepsy with only $6 \%$ of the cases reporting a low quality of life. However, all the cases in the study had well-controlled epilepsy and it is suggested that a low quality of life may be a major problem only in individuals with refractory epilepsy (1).

Families with children with epilepsy in developing countries are faced with the added burden of poverty, ignorance, poor sociocultural beliefs and practices which pose additional challenges to coping with the disease (3). Consequently, poor compliance with therapy, limited availability of anti-epileptic drugs (AEDs) and/or poor quality control of locally produced AEDs may lead to the vicious cycle of seizure recurrences and its attendant psychosocial burden in both the child with epilepsy and family of care givers (13) .

The psychosocial impact of diseases varies with sociocultural settings. This study was therefore undertaken to evaluate the health related quality of life (HRQOL) and the psychosocial problems associated with epilepsy in both the children with epilepsy and their parents in Nigeria.

\section{MATERIALS AND METHODS}

During a 3 month period, all consecutive cases of epilepsy aged 5years and above who had been attending the paediatric neurology clinic of the University College Hospital, Ibadan, Nigeria for at least 6months were recruited into the study. Epilepsy was defined as separate occurrence of two or more unprovoked seizures, not diagnosed as neonatal or febrile seizures (11). The diagnosis of epilepsy in the children was based on history from a reliable eye witness account, the patient's account and the EEG findings as all the children had 
electroencephalography (EEG) done. Seizure types and epilepsy disorders in these patients was based on the International classification of epileptic seizures, epilepsies and epileptic syndromes of the League against Epilepsy (ILAE) (1993) (11).

After informed consent was obtained from the caregivers, information obtained on each patient included; age, sex, age at onset of seizures, frequency of seizures, anti-epileptic drug treatment, drug compliance, parents'/caregivers occupation and level of education.

Standard questionnaires, adapted from the PedsQL Questionnaire (13) were administered to the children and their caregivers. The questionnaire contained questions which assessed the following; general health, physical functioning, limitations in school functioning, behavioural and mental health, family life and self esteem. General health was assessed in terms of seizure type, seizure frequency, reaction to anti-epileptic drugs (AED) and the child's perception of his health or well-being. The physical functioning was measured in terms of completion of age-appropriate physical tasks, leisure activity participation, engagement in activities such as sports, clubs, hobbies, household chores and physical injuries from epilepsy. School activity was assessed in terms of academic achievement, deterioration in academic performance following commencement of AED, learning problems and school absenteeism. Impact of epilepsy on behaviour was assessed in terms of family relationships, peer relationships and abnormal behavioural tendencies. The child's mental health was measured in terms of the emotional status, feelings about epilepsy, attitude towards having epilepsy, concerns, fears, anxiety, worries and depression. Self esteem was assessed in terms of the child's feeling of self worth and perceptions of stigma. Impact of epilepsy on family life was measured in terms of emotional and time impact on parents, marital disharmony, separations, divorces, loss of employment, disruption of routine family schedule and leisure activities and impact on other children in the family. Scores, ranging from 1 to 5 were assigned to rate the severity of impact of the illness. All the scores in the various domains were added and divided by 6 to determine the mean score. The mean score taken to the nearest whole number was taken as the measure of the impact of epilepsy on the overall HRQOL. A score of 1 implied no impact while a score of 5 implied the worst impact on the criterion being assessed. A total of 4-5 questions were used to test each of the domains, with each parameter having scores ranging from 1 to 5 . The average score for each domain was obtained by summing up all the scores and dividing the sum by the total number of questions answered. Data was analysed using SPSS 12 for windows software and data summarization was done using proportions, means, median and standard deviation depending on the units of the variables. Categorical variables were compared using the Chi square test. Level of significance was set 0.05 .

\section{RESULTS}

A total of 66 children, 33 males and 33 females, were recruited into the study, giving a male to female ratio of 1:1. The age of the patients ranged from 60 to 180 months with a mean (SD) of 99.5 (35.4) months. Generalised tonic clonic seizure was the most common type of seizure seen in $42.4 \%$ while complex partial seizures and absence seizures were diagnosed in $16.6 \%$ and $12.1 \%$ respectively (Table 1 ). Fifty six (84.8\%) children were from monogamous family settings while $10(15.2 \%)$ were from polygamous family settings. Eight $(12.1 \%)$ of the 66 children had symptomatic epilepsy while the remaining $58(87.9 \%)$ had idiopathic epilepsy.

\section{General health}

Twenty $(30.3 \%)$ of the children had severe epilepsy, as defined by a seizure frequency of more than one attack per month. Five $(7.6 \%)$ gave a history of undesirable side effects of the AED. General health was profoundly affected in $15(22.7 \%)$ children and optimal in $21(31.8 \%)$ children (Table 2$)$.

\section{Physical functioning}

The majority $(69.7 \%)$ of the children did not have limitation of physical functioning while some limitation was reported in $20(30.3 \%)$ of the cases. Only a few were severely (3\%) and profoundly (3\%) affected. (Table 2 ). Seven $(10.6 \%)$ children reported previous injuries sustained during epileptic attacks.

\section{Limitation in school activity}

Thirty five (53.0\%) of the children did not experience any form of limitation in school work, while 7 (10.6\%) reported severe to profound limitation in school work, with $4(6.1 \%)$ having to drop out of school on account of severe epilepsy. The remaining $24(36.4 \%)$ reported missing school occasionally as a result of seizures. Deterioration in academic performance was reported in $12(18.2 \%)$ of the children and play activities was found to be affected in nine (13.6\%) of the cases. 


\section{Behaviour and Mental Health}

Poor peer relationship was reported in $8(12.1 \%)$ children, with feelings of envy of non epileptic children and dislike for their peers including physical fights with other children. Fourteen $(21.2 \%)$ of the caregivers reported abnormal behavioural tendencies in the cases studied. Thirty two $(48.6 \%)$ of the cases expressed concerns about having the disease. Of these, feelings of sadness was reported in $18(27.3 \%)$, worries in $15(22.7 \%)$ and feelings and expressions of fear in $13(19.7 \%)$. Seven $(10.6 \%)$ of the children, all of whom had severe epilepsy reported feelings of being fed up with life. Feelings of stigmatization were reported in 23 (34.8\%) cases.

\section{Self esteem}

Twenty three (34.8\%) of the children reported some loss of self esteem or inadequacy and feelings of stigmatization. These feelings affected their relationship with friends in school and in the neighborhood.

\section{Family life}

Fourteen $(21.2 \%)$ of the parents reported a significant impact on the time spent on the care of the epileptic child, with resultant loss of income and other financial benefits. Ten (15.2\%) of the mothers have had to stop working in order to have adequate time to take care of their children with epilepsy. Siblings of the children with epilepsy in five $(7.6 \%)$ families had experienced parental neglect on account of the time spent by their parents in caring for the affected child. Fourteen of the families $(21.2 \%)$ had taken a loan to meet up with the expenses of managing the affected child and $10(24.2 \%)$ of the families experienced tension in the home as a result of having an epileptic child while nine $(13.6 \%)$ of the parents, mainly mothers, experienced feelings of guilt.

Disruption of family cohesion was reported in $33(50 \%)$ of the cases, with frequent quarrels and disagreements. Marital disharmony with consequent divorce was reported in $5(7.6 \%)$ of the families. Eight $(12.1 \%)$ of the children had been sent to other members of the extended family because the parents could not cope with the stress of caring for the child with epilepsy.

The study showed a statistically significant association between seizure severity $(p=0.000)$ and parental emotional impact $(p=0.015)$ and impaired HRQOL in the epileptic children. A statistically significant association was also found between maternal level of education and impaired HRQOL $(P=0.034)$, with children of mothers with lower than secondary education having a poorer HRQOL. There was no statistically significant association between gender and HRQOL (0.789). Seizure severity of at least one attack/month remained an independent predictor of impaired HRQOL after controlling for maternal education and parental emotional impact. (Tables $3 \& 4$ )

\section{DISCUSSION}

Holistic approach to management of diseases emphasizes positive outcomes of care. In childhood epilepsy, the goal of management has traditionally been defined by optimal seizure control, however, the assessment of HRQOL of epileptic children or any chronic disease has become a major public health issue. The HRQOL is generally measured in terms of a person's state of functioning and well being across multiple dimensions. This study demonstrated as in others $(4,8,19)$ that epilepsy has a major impact on the HRQOL of Nigerian children, with significant impairments in at least one-quarter of the cases in all the domains tested. The general health was found to be adversely affected by epilepsy as only one-third of the cases assessed their health as optimal. The poorest ratings were found in cases with severe epilepsy and this is consistent with previous reports $(1,9)$ which have described seizure severity as a major predictor of HRQOL in epilepsy. Physical functioning defined by play, exercise and domestic chores was rated as optimal in two thirds of the cases but impaired in a third of the children. These functioning are important elements in daily living of children and impairment in these areas have been shown to be associated with frustration and abnormal behavioural tendencies $(4,8,19)$. About one quarter of the children experienced varying degrees of stress on their mental health and abnormal behavioural tendencies which are consistent with the findings of Freilinger et al (8) who reported behavioural and emotional problems in about $22.2 \%$ of a cohort of epileptic Austrian children. Wagner and Smith (19) also described behavioural problems as the overall most common reason for referral to psychological services in a cohort of 84 epileptic children referred to an on-site paediatric psychologist.

Children with epilepsy are known to be vulnerable to educational problems and resultant academic underachievement $(7,10)$ and this study demonstrated impairment in school activity and academic skills in nearly half of the cases evaluated. Academic underachievement in this study as in other reports $(7,10,16)$ may be attributed to a combination of factors acting individually or synergistically which include the deleterious effects of repeated seizures on the developing brain, behavioural problems, psychosocial issues 
and the effect of antiepileptic drugs.. The epilepsy in these children impacted significantly on the emotion and time of the parents of these children as well as family cohesion. It is also noteworthy that the presence of an epileptic child in the family precipitated divorce in 5 of the 66 families and studies from other sociocultural backgrounds have also confirmed negative effects on family cohesion as well as increased rates of divorce (5). This fractured family cohesion may be related to the lack of social support services and misconceptions about the disease including the fact that epilepsy is believed in this society to be infectious and therefore transmissible or inheritable (14,20). Other issues that may impact on family cohesion are financial hardship related to managing the epileptic child and stigmatization of Nigerian patients and parents (14,20). Traditionally, the extended family system in Africa is believed to have a positive influence on marital stability but the findings in this study suggests that this protective effect does not appear to be sufficient to overcome the destabilizing effect of having an epileptic child in the family.

This study showed significant association between seizure severity and parental emotional impact and impaired HRQOL in the epileptic children. This finding is in agreement with Connolly et al (4) who described parental emotional impact as a major predictor of impaired HRQOL in Welsh children with benign Rolandic epilepsy. Maternal educational level and economic ability in this study showed a statistically significant association with the HRQOL, with children of mothers with less than 10 years of formal education having a poorer HRQOL. In a society that places great premium on the male child, interestingly there was no statistically significant association between gender and HRQOL.

Predictors of impaired HRQOL found in the study were severe epilepsy and family disruption. Optimal seizure control with AED is essential for long term care of children with epilepsy. However, impaired HRQOL is also a major issue in Nigerian children with epilepsy that has not been fully integrated into the care of such children. This study confirms the need for routine screening, counseling and psychosocial support for cognitive, emotional and physical health problems of children with epilepsy. This study also confirms the need for counseling therapy and social support groups for the families of children living with epilepsy.

Table 1. Pattern of seizures in the 66 children with epilepsy

\begin{tabular}{|l|c|c|}
\hline \multicolumn{1}{|c|}{ Seizure Types } & $\boldsymbol{n}$ & $\%$ \\
\hline Generalised tonic-clonic & 28 & 42.4 \\
\hline Complex partial seizures & 11 & 16.6 \\
\hline Absence seizure & 8 & 12.1 \\
\hline Partial seizures secondarily generalized & 7 & 10.6 \\
\hline Myoclonic epilepsy & 4 & 6.1 \\
\hline Atonic seizures & 4 & 6.1 \\
\hline Mixed seizures & 4 & 6.1 \\
\hline Total & 66 & 100.0 \\
\hline
\end{tabular}


Table 2. Quality of life rating in the 66 cases of epilepsy

\begin{tabular}{|l|l|l|l|l|l|l|l|l|l|l|}
\hline & $\boldsymbol{I}$ & & $\boldsymbol{I I}$ & & III & & $\boldsymbol{I V}$ & & $\boldsymbol{V}$ & \\
\hline & $\boldsymbol{n}$ & $\boldsymbol{\%}$ & $\boldsymbol{n}$ & $\boldsymbol{\%}$ & $\boldsymbol{n}$ & $\boldsymbol{\%}$ & $\boldsymbol{n}$ & $\boldsymbol{\%}$ & $\boldsymbol{n}$ & $\%$ \\
\hline General health & 21 & 31.8 & 20 & 30.3 & 5 & 7.6 & 5 & 7.6 & 15 & 22.7 \\
\hline Physical functioning & 46 & 69.7 & 13 & 19.7 & 3 & 4.5 & 2 & 3.0 & 2 & 3.0 \\
\hline School activity & 35 & 53.0 & 19 & 28.8 & 5 & 7.6 & 1 & 1.5 & 6 & 9.1 \\
\hline Behavioural \& mental health & 48 & 72.7 & 12 & 18.2 & 1 & 1.5 & 4 & 6.1 & 1 & 1.5 \\
\hline Self esteem & 43 & 65.2 & 11 & 16.7 & 1 & 1.5 & 6 & 9.1 & 5 & 7.6 \\
\hline Family life & 30 & 45.5 & 18 & 27.3 & 6 & 9.1 & 7 & 10.6 & 5 & 7.6 \\
\hline
\end{tabular}

$\mathrm{I}=$ not affected, II= mildly affected, III = moderately affected, IV= severely affected $\mathrm{V}=$ profoundly affected

Table 3: Relationship between HRQOL and seizure severity and selected demographic variables

\begin{tabular}{|c|c|c|c|c|c|c|c|}
\hline Factors & $\begin{array}{c}\text { Quality of } \\
\text { life:Impaired } N=46\end{array}$ & & $\begin{array}{c}\text { Quality of life: Not } \\
\text { impaired/good } N=20\end{array}$ & & $p$ & $R R$ & $95 \% \mathrm{Cl}$ \\
\hline $\begin{array}{l}\text { Frequent seizures } \geq 1 \\
\text { per month }\end{array}$ & 41 & 89.1 & 3 & 15.0 & 0.000 & 4.20 & $\begin{array}{l}1.94 \\
9.09\end{array}$ \\
\hline $\begin{array}{|ll|}\begin{array}{l}\text { Parental emotional } \\
\text { impact }\end{array} & \\
\end{array}$ & 16 & 34.8 & 14 & 70.0 & 0.015 & 0.23 & $\begin{array}{l}0.07 \\
0.71\end{array}$ \\
\hline $\begin{array}{l}\text { Maternal education } \\
<10 \text { year }\end{array}$ & 25 & 54.3 & 5 & 25.0 & 0.034 & 1.43 & $\begin{array}{l}1.04 \\
1.97 \\
\end{array}$ \\
\hline Family separation & 2 & 4.3 & 4 & 20.0 & 0.063 & 0.45 & $\begin{array}{l}0.15 \\
1.42 \\
\end{array}$ \\
\hline Low social class & 5 & 10.9 & 6 & 30.0 & 0.075 & 0.61 & $\begin{array}{l}0.31 \\
1.19\end{array}$ \\
\hline Male & 22 & 47.8 & 11 & 55.0 & 0.789 & 0.75 & $\begin{array}{l}0.26 \\
2.15\end{array}$ \\
\hline
\end{tabular}

RR - Risk ratio; $95 \% \mathrm{Cl}$ - Confidence interval

Table 4: Logistic regression analysis of factors associated with impaired QOL

\begin{tabular}{|l|c|c|c|l|l|}
\hline \multicolumn{1}{|c|}{ Variables } & $\boldsymbol{\beta}$ & S.E & $\boldsymbol{p}$ & $\operatorname{Exp}(\boldsymbol{\beta})$ & \multicolumn{1}{|c|}{ 95\% CI $\operatorname{Exp}(\boldsymbol{\beta})$} \\
\hline Parental emotional impact & -4.191 & .930 & 0.000 & 0.015 & $0.02,0.09$ \\
\hline Frequent seizures $\geq 1$ per month & 0.798 & .882 & 0.365 & 2.221 & $0.39,12.50$ \\
\hline Maternal education $<12$ year & -0.014 & .966 & 0.989 & 0.986 & $0.15,6.54$ \\
\hline Constant & 1.227 & .845 & 0.147 & 3.410 & - \\
\hline
\end{tabular}




\section{REFERENCES}

1. ALDENKAMP AP, VANDONSELAAR CA, FLAMMAN H, LAFARRE DL. Psychosocial reactions to the epilepsy in an unselected group of patients with epilepsy under treatment in General Hospitals. Seizure 2003;12: 101-106

1. BERTOLOTE JM. Epilepsy as a public health problem. Trop Geogr Med 1994; 46: 28-30.

2. BRIBECK GL. Barriers to care for patients with neurologic disease in rural Zambia. Arch Neurol 2000;57:414-417.

3. CONNOLLY AM, NORTHCOTT E, CAIRNS DR. Quality of life of children with bening rolandic epilepsy. Pediatr Neurol 2006;35:240-245

4. DAS K, BANERJEE M, MONDAL G, DEVI L, SINGH O, MUKHERJEE B. Evaluation of socioeconomic factors causing discontinuation of epilepsy treatment resulting in seizure recurrence: A study in an urban epilepsy clinic in India. Seizure 2003;16:601-607.

5. DE SOUZA EA, SALGADO PC. A psychosocial view of anxiety and depression in epilepsy. Epilepsy Behav 2006;8:232-238.

6. FATENAU PS, JIANZHAO SHEN, DUNN DW, AUSTIN JK. J Learn Disabil 2008;41:195-207

7. FREILINGER M, REISEL B, REITER E, ZELENCHO M, HAWER E, SEIDL R. Behavioural and emotional problems in children with epilepsy. J Child Neurol 2006;21:939-945

8. HOIE B, SOMMERFELT K, WAALER PE, ALSAKER FD, SKEIDROLL H, MYKLETUN A. Psychosocial problems and seizure-related factors in children with epilepsy. Dev Med Child Neurol 2006;48:213-219

9. IBEKWE RC, OJINNAKA NC, ILOEJE SO. Factors influencing the academic performance of school children with epilepsy. J Trop Pediatr 2007;53: 338-343

10. International League Against Epilepsy Commission on Classification and Terminology of The International League Against Epilepsy. Proposal for Revised Classification of Epilepsies and Epileptic Syndromes. Epilepsia 1989; 30:389-399.

11.JALLON P. Epilepsy in developing countries. Epilepsia 1997;38:1143-1151.

12.JAMES W. VARNI. The pedsQLTM Measurement Model for the Pediatric Quality of Life Inventory. http://www.pedsql.org/ (Accessed 5th June,2008)

13.JILEK-AALL L, JILEK W, KAAYA J, MKOMBACHEPA L, HILLARY K. Psychosocial study of epilepsy in Africa. Social Science and Medicine 1997;45: 783-795.

14.MACLEODS JS, AUSTIN JK. Stigma in the lives of adolescents with epilepsy: a review of literature. Epilepsy Behav 2003;4:112-117.

15.MCNELIS AM, DUNN DW, JOHNSON CS, AUSTIN JK, PERKINS SM. Academic performance in children with new onset seizures and asthma: a prospective study. Epilepsy Behav 2007;10:311318.

16.MEINARDI H, SCOTT RA, REIS R, SANDER JW. The treatment gap in epilepsy: The current situation and ways forward. Epilepsia 2001;42:136-149.

17.RODENBURG R, STAMS GJ, MEIJER AM, ALDENKAMP AP, DEKOVIC M. Psychopathology in children with epilepsy: a meta-analysis. J Pediatr Psychol 2005;30:453-468.

18.WAGNER JL, SMITH G. Psychological services in a pediatric epilepsy clinic: Referral patterns and feasibility. Epilepsy Behav 2007:10: 129-133.

19.WANDRA T, SUBAHAR R, SIMANJUNTAK GM, et al. Resurgences of cases of epileptic seizures and burns associated with cysticercosis in Assologaima, Jayawijaya, Irian Jaya, Indonesia, 19911995. Trans Roy Soc Trop Med Hyg 2000;94:46-50. 